\section{Requiem for international medical graduates}

These men ask for just the same thing - fairness, and fairness only. This, so far as in my power, they, and all others, shall have.' Abraham Lincoln

The Department of Health, in conjunction with the Home Office, announced critical changes to immigration rules for international medical graduates from outside of the European Economic Area, which came into force in April. ${ }^{1-3}$ Until then, rules of immigration in the UK had fostered training of international medical graduates through the proviso of a permit-free training visa. By virtue of the new decree, this training visa will no longer be issued. Instead, overseas applicants will need work permits, ${ }^{4}$ if they do not have a right to live and work in the UK otherwise. To procure a work permit for an international medical graduate, trusts and deaneries must demonstrate to the Home Office that there are no suitable home-grown graduates available for the post. ${ }^{2}$ The crux of the problem understandably, lies here; hereafter, an applicant's country of origin and visa status will take predominance over merit and distinctions. Training opportunities for overseas doctors will become limited. What is indeed astounding, is the fact that these substantial changes have been unleashed with little warning and with retrospective effect, and will affect even those in training.

The ruling will expedite recruitment processes, as trusts and deaneries will now sift through a far fewer number of applications. It may also usher in a sense of relief for British graduates, by mitigating the frenzied job situation. For international medical graduates though - many of whom are already facing monetary and emotional hardship - it may be the final nail in the coffin. Entry into foundation programmes for most will remain a forlorn dream. Those already in foundation programmes or senior house officer posts may never make the leap to specialist training. They may suddenly find themselves in a unique predicament with neither post-graduate degrees nor specialist skills. With bleak prospects and without visas, they may be forced to leave the country. It may be particularly disheartening for those doing research (some on an honorary basis), in order to bolster their credentials. Academic distinctions may not lead to interviews and jobs anymore. Their meticulous work of several years duration may never bear fruit.

Certain transitional arrangements have been made for doctors currently on permit-free training. Their current employers will procure a work permit for the remaining period of their employment. However, these candidates will find themselves checkmated by the new ruling when applying for their next training position. For such grants right to work in the UK, may provide a solution. But, those qualifying through this programme are only given short-term visas which may restrict them from being considered for long-term training posts. Furthermore, scoring the required points for qualification through this programme, is not easy for the relatively inexperienced. Returning to one's country of origin is another option. If one is indeed determined about specialist training and foreign degrees, migrating to USA or Canada may help realize these ends. Needless to say, both these options will set the clock back by a few years. The final recourse will probably be to settle for non-career grade or other less preferred posts in the UK.

Despite vicious competition in the job market and alarming rates of unemployment among overseas doctors, ${ }^{6}$ the General Medical Council, for reasons that are enigmatic, has continued to conduct the Professional and Linguistics Assessments Board test; and that, on a rip-roaring scale. ${ }^{7}$ Has the honourable institution been ignorant of this glut or is it resolute on selling an expensive ticket to fool's paradise? Why did the Department of Health not anticipate this overabundance a few years ago and introduce these measures then, by degrees? It could have spared thousands from this misadventure.

'There are no equal opportunities anymore' - is the quintessence of this unsavoury issue. It is indeed lamentable that Great Britain, the illustrious leader of the Commonwealth, should adopt this stance. Doctors from Commonwealth countries, have been an integral force in the National Health Service for decades. Suddenly, they have been unceremoniously sidelined. The well-being of British graduates certainly needs to be ensured, but not by culling others' careers. Are overseas doctors simply dispensable dogsbodies?

The sword of Damocles already hangs over the heads of international medical graduates in the guise of Modernising Medical Careers. ${ }^{8}$ The new immigration rules might just terminate their prospects in one swift stroke. Lives and livelihoods will be ruined. Many have already spent a substantial number of years to kick-start their careers in the UK. It will be heartbreaking for them to accept the fact that they may have to relinquish everything and start all over again. Will they ever realize their goals, their dreams? These stringent immigration rules, will leave countless bright young minds to face a grim and nebulous future.

Competing interests Both authors are international medical graduates.

\footnotetext{
Arun Natarajan ${ }^{1}$

Balasubramanian Ravikumar ${ }^{2}$

1DRWF Clinical Research Fellow, School of Clinical Medical Sciences, University of Newcastle, Newcastle upon Tyne NE2 4HH; ${ }^{2}$ Specialist Registrar in Diabetes and Endocrinology, Newcastle General Hospital Newcastle upon Tyne, UK

Correspondence to: A Natarajan

E-mail: Arun.Natarajan1@newcastle.ac.uk
} 


\section{REFERENCES}

1 Extra investment and increase in home-grown medical recruits eases UK reliance on overseas doctors. Department of Health press release notice 7 March 2006 [http://www.dh.gov.uk/PublicationsAndStatistics/ PressReleases/PressReleasesNotices/fs/en?CONTENT_ID $=4131255 \&$ chk=TadpQg]

2 Business and Commercial Occupation Sheet Index. Home Office Policy Instructions [http://www.workingintheuk.gov.uk/ind/en/home/ laws_policy/policy_instructions/business_and_commercial/business_and_ commercial0.Maincontent.0061.file.tmp/postgraddoctorsdentists.pdf]

3 Changes to the immigration rules for postgraduate doctors and dentists. Publication from Conference of Postgraduate Medical Deans [http:// www.copmed.org.uk/document_store/1142527475lAnx_changes_to_ the_immigration_rules_for_postgraduate_doctors_and_dentists.doc]

4 Work Permits (UK) [http://www.workingintheuk.gov.uk]

5 Highly Skilled Migrant Programme [http://www. workingintheuk.gov.uk/ working_in_the_uk/en/homepage/schemes_and_programmes/hsmp.html]

6 Thinking of coming to the UK to take part 2 of the PLAB examination? [http://www.rcplondon.ac.uk/International/ news02MedicalGraduates.asp]

7 [http://www.gmc-uk.org/doctors/plab/availability.asp]

8 Modernizing medical careers [http://www.mmc.nhs.uk/pages/ careers/overseas-doctors]

\section{Complicity theory: an explanation for the 'coxib problem'?}

The 'coxib' controversy continues to rage. In addition to articles in this and other journals, ${ }^{1,2}$ there are ongoing lawsuits and continuing media coverage. In this month's journal we hear of more inconsistencies in the reporting of adverse events in trials of celecoxib. ${ }^{3}$

The basic coxib idea is a good one. Non-steroidal antiinflammatory drugs (NSAIDs), which work by inhibition of cyclo-oxygenase(COX), are valuable drugs for people with inflammatory disorders. We know that there are two COX enzymes that are involved in inflammation, and that only one of them protects the gastro-intestinal tract. So it makes sense to look for selective inhibitors that might have antiinflammatory and analgesic properties, without causing gastrointestinal problems. And the idea works, perhaps even better than we expected, as some of the coxibsCOX-2 inhibitors - seem to have superior analgesic properties to their COX-1 inhibiting ancestors (the traditional NSAIDs), and they do seem to cause less gastrointestinal problems. ${ }^{4}$ The problem, as just about everyone in the world now knows, is that coxibs come with the price of an increase in cardiovascular adverse events. This should not have come as a surprise. The possibility of an increased risk was known about long before the now infamous CLASS and VIGOR studies, ${ }^{5,6}$ as it was a theoretical complication of COX-2 inhibition highlighted by Fitzgerald's group and others in the 1990s. ${ }^{7}$

The increase in cardiovascular adverse events with coxib use may not be as big a problem as has been suggested. Clearly there is an increased risk of myocardial infarction in those who take some coxibs. ${ }^{1}$ But the risk is not huge, and the numbers of events caused relatively small. Furthermore, if we were to avoid using them in those with other risk factors for cardiovascular disease, the increase in absolute risk for any given individual would probably be marginal. It is hard to balance the risk of a fatal adverse event in a few, against major symptomatic benefit in the majority, ${ }^{8}$ but many of our patients would clearly opt for the symptomatic relief. So, the logical strategy for those who need an antiinflammatory agent is to use coxibs in those who have risk factors for gastrointestinal problems and a traditional NSAID for this with cardiovascular risk factors. But most of us are not doing that. First, we have allowed the longstanding rhetoric surrounding all NSAIDs to convince us to use them for any sort of painful problem, whether inflammation exists or not - so the indications for their use have expanded. ${ }^{9}$ Second, a series of scandals surrounding all types of NSAID have altered our perceptions and behaviours. The public have now lost confidence and the professionals are confused. Some are pursuing the 'wicked' pharmaceutical industry, many are nervous of coxibs, and some are giving up using NSAIDs altogether.

There are generally two schools of thought on how we get into a mess of this sort: the conspiracy theory and the cock-up theory. I generally believe in cock-up rather than conspiracy. But in this case there has been much talk about conspiracy and cover-ups within the industry. One can see why. The potential profits that can come from a good antiinflammatory drug are enormous, and it is sometimes hard to believe that any drug company would not be 'influenced' by the prospect of those profits. And I think their marketing divisions have been. The money and expertise that went into the launches of celecoxib and rofecoxib was truly obscene. The more serious accusation is that the science done by and for the industry has also been biased and corrupted by these financial interests. Maybe it has, but little direct evidence has emerged to support such accusations. In this instance, I believe the main problem belongs within the province of a third 'how-to-get-into-amess-like-this-one' theory-complicity theory. ${ }^{10}$

Complicity works like this. All those with a vested interest in an enterprise get sucked into the rhetoric associated with it, and they soon 'believe' in everything that is going on within that enterprise. If personal financial gain is involved, corruption may also occur. So, in the case of drugs such as anti-inflammatory agents, researchers and prescribers work with the industry to promote the 
development, testing and use of these drugs. Personal financial gains come through company shares, consultancies and free trips to exotic locations (for those who do research or actively promote the drugs), trips to educational meetings (for specialists), or 'just' free lunches (for just about everybody - does any doctor still buy his/her own lunch?). ${ }^{11}$ If this goes on for long enough (and it has), everyone starts to believe that they are doing the right thing when they accept company largesse, and to believe in the drugs. And they do not realize that their ability to look at data critically, and at drug use objectively, has been compromised. So, when data comes along that says that rofecoxib causes heart attacks, lots of people say 'wait a minute, rofecoxib is wonderful, so maybe the explanation for this is that the NSAID comparator (naproxen) is also a wonder drug and is protecting people against heart attacks'. ${ }^{12}$ The marketing pressures make all of this worse, of course. So when a paper gets published that says that celecoxib is wonderful, it gets distributed to everyone (as they attend the free lunch event). And when it turns out that the data are flawed (fraud?) the papers still go on being distributed to everyone. ${ }^{13}$

The pharmaceutical industry has developed a position of extraordinary power over governments, medical research and medical practice. ${ }^{14,15}$ But complicity theory makes it clear that this would not have been possible without others going along with their story. Doctors have been terrible in that regard; we now work in an industry where companies who stand to profit from our activities sponsor most of our postgraduate education. Politicians are also to blame. For example, Gordon Brown is campaigning to keep the pharmaceutical industry in Britain, to help 'UK plc', and one result of that is that all of us (including Medical Research Council scientists like myself), are being encouraged to work with the industry.

The complicity of politicians and health professionals with the pharmaceutical industry agenda, driven by the profit motive, has made us all blind to data and to common sense. For example, there is now widespread use of drugs (including NSAIDs and coxibs) for problems that are largely social, behavioural or mechanical in origin and the prevention and treatment of which is more logically approached through behavioural interventions than by the use of drugs. ${ }^{16}$ Most current medical research, as well as medical practice, is dominated by the vested interests of the multi-national pharmaceutical industry, which is now busy inventing diseases for which it can find drugs. ${ }^{17}$ We now live in a medical culture that appears to have become completely drug dependent - because of money. How bad is that?
Acknowledgments I should like to thank Jonathan Sterne for help and advice when preparing this piece.

\section{Competing interests None}

\section{Paul Dieppe}

Department of Social Medicine, University of Bristol, Bristol BS8 2PR, UK E-mail: P.Dieppe@bristol.ac.uk

\section{REFERENCES}

1 Caldwell B, Aldington S, Weatherall M, Shirtcliffe P,Beasley R. Risk of cardiovascular events and celecoxib: a systematic review and metaanalysis. J R Soc Med 2006;99:132-40

2 Curfman G, Morrissey S, Drazen J. Expression of Concern Reaffirmed. N Engl J Med 2006;354:1193

3 Weatherall M, Aldington S, Caldwell B, Beasley R. Inconsistencies in cardiovascular data from COX-2 inhibitor trials - is it a CLASS effect? $J$ R Soc Med 2006;99:275-6

4 Hawkey C, Langman M. Non-steroidal anti-inflammatory drugs: overall riks and management. Complementary roles for COX-2 inhibitors and proton pump inhibitors. Gut 2003;52:600-8

5 Silverstein FE, Faich G, Goldstein JL, et al. Gastrointestinal toxicity with celecoxib vs nonsteroidal anti-inflammatory drugs for osteoarthritis and rheumatoid arthritis: the CLASS study. JAMA 2000;284:1247-55

6 Bombardier C, Laine L, Reicin A, et al. Comparison of upper gastrointestinal toxicity with rofecoxib and naproxen in patients with rheumatoid arthritis. VIGOR study group. N Engl J Med 2000;343: 1520-8

7 McAdam B, Catella-Lawson F, Mardini I, Kapoor S, Lawson J, Fizgerald G. Systemic biosynthesis of prostacyclin by cyclooxygenase (COX)-2: the human pharmacology of a selective inhibitor of COX-2. Proc Nat Acad Sci 1999;96:272-7

8 Dieppe P, Bartlett C, Davey P, Doyal L, Ebrahim S. Balancing benefits and harms: the example of non-steroidal anti-inflammatory drugs. $B M J$ 2004;329:31-4

9 Dieppe P, Ebrahim S, Martin R, Juni P. Lessons from the withdrawal of rofecoxib. BMJ 2004;329:867-8

10 Kline A. On complicity theory. Sci Eng Ethics 2006;12:257-64

11 [http://www.nofreelunch.org]

12 Watson D, Rhodes T, Cai B, Guess H. Lower risk of thromboembolic cardiovascular events with naproxen among patients with rheumatoid arthritis. Arch Intern Med 2002;162:1105-10

13 Juni P, Rutjs AW, Dieppe PA. Are selective COX 2 inhibitors superior to traditional non steroidal anti-inflammatory drugs? BMJ 2002;324:1287-8

14 Angell M. The Truth About The Drug Companies: How They Deceive Us and What To Do About It. London: Random House, 2005

15 Weber L. Profits Before People?: Ethical Standards and The Marketing and Prescription of Drugs. Indiana: Indiana University Press, 2006

16 Marteau T, Dieppe P, Foy R, Kinmonth AL, Schneiderman N. Behavioural medicine: changing our behaviour. BMJ 2006;332:437-8

17 Moynihan R, Cassels A. Selling Sickness: How The World's Biggest Pharmaceutical Companies Are Turning Us All Into Patients. California: Avalon Publishing Group, 2005 